\title{
What Is the Potential Role of Transcutaneous Carbon Dioxide in Guiding Acute Noninvasive Ventilation?
}

Transcutaneous monitoring has been used in the clinical setting to assess both oxygenation $\left(\mathrm{P}_{\mathrm{tcO}_{2}}\right)$ and ventilation $\left(\mathrm{P}_{\mathrm{tcCO}_{2}}\right)$. Because pulse oximetry is considered to be the standard of care for assessing oxygenation noninvasively, much of the more recent focus on transcutaneous monitoring has been on $\mathrm{P}_{\mathrm{tcCO}_{2}}$. Unlike $\mathrm{P}_{\mathrm{tcO}_{2}}$ monitoring, which requires the skin probe to be heated to $44^{\circ} \mathrm{C}$, putting patients at risk for skin burns, $\mathrm{P}_{\mathrm{tcCO}_{2}}$ monitoring has been shown to be effective with skin temperatures as low as normal body temperature $\left(37^{\circ} \mathrm{C}\right) . \mathrm{P}_{\mathrm{tcCO}_{2}}$ monitoring has been used frequently with infants and children who require high-frequency ventilation. ${ }^{1}$

For transcutaneous monitoring to produce valid results, the device must first be calibrated, and a sensor/monitoring site chosen. Capillaries are hyperperfused by elevating the temperature of the skin at the site where the sensor is placed. Attaching the sensor to a vascularized site is necessary to obtain useful results. When using either $\mathrm{P}_{\mathrm{tcCO}}$ or end-tidal $\mathrm{P}_{\mathrm{CO}_{2}}$, it is strongly recommended that the results be compared with arterial blood gases to ensure accuracy and reliability of the results. One difficulty associated with monitoring $\mathrm{P}_{\mathrm{tcCO}}$ is that there is a delay in obtaining readings due to stabilization of the transcutaneous monitoring device. ${ }^{2}$

In a previous study, Storre et $\mathrm{al}^{3}$ investigated the capability of $\mathrm{P}_{\mathrm{tcCO}}$ monitoring to reliably assess alveolar ventilation in stable subjects who required nocturnal noninvasive ventilation (NIV) support. The results of the study showed that differences between transcutaneous and arterial $\mathrm{P}_{\mathrm{CO}_{2}}$ levels were minimal and that nocturnal $\mathrm{P}_{\mathrm{tcCO}}$ monitoring is a reliable and effective tool for monitoring alveolar ventilation during sleep in subjects with chronic hypercapnic respiratory failure.

In this issue of Respiratory Care, van Oppen et $\mathrm{al}^{4}$ describe a prospective observational study to assess the potential of $\mathrm{P}_{\mathrm{tcCO}}$ to calculate $\mathrm{pH}$ and to guide the management of NIV in subjects with acute hypercapnic respiratory failure. Although the study sample size was small,

\footnotetext{
Mr Nuccio has disclosed no conflicts of interest.
}

Correspondence: Paul F Nuccio MSc RRT FAARC, Department of Respiratory Care, Brigham and Women's Hospital, 75 Francis Street, Boston, MA 02115. E-mail: pnuccio@partners.org.

DOI: $10.4187 /$ respcare.04030 the results demonstrated the potential for noninvasive monitoring as an alternative to the more painful and costly blood sampling when caring for patients requiring NIV for acute hypercapnic respiratory failure.

See the Original Research on Page 484

One of the goals of van Oppen et $\mathrm{al}^{4}$ was to compare pain levels associated with arterial blood gas sampling and transcutaneous monitoring technology. The authors stated that a during a COPD exacerbation, it is necessary to obtain arterial blood samples to measure $\mathrm{pH}$. They evaluated the calculation of noninvasive $\mathrm{pH}$ by using the Henderson-Hasselbalch equation and a bicarbonate calculation algorithm. Is it really necessary to perform serial arterial blood gases to adequately assess ventilation during NIV? Some clinicians believe that this may not be necessary if other signs and symptoms are closely monitored, such as breathing frequency, perceived work of breathing, and presence or absence of diaphoresis.

van Oppen et $\mathrm{al}^{4}$ found that subjects who required NIV preferred transcutaneous to arterial blood gas monitoring. The authors referred to arterial blood gas sampling as being more time-consuming and painful for subjects. Although this may be true to a certain extent, it may be difficult to draw the inference about pain when the subjects being studied had arterial lines in place as a means to obtain the samples.

There may be a benefit of using transcutaneous monitoring for these patients, although the devices used at present are quite costly. A less expensive option may be sidestream capnography. At present, there are issues related to sampling site and mask leaks and how these issues may influence the practical use of this technology.

As mentioned by van Oppen et $\mathrm{al},{ }^{4}$ further research is necessary to validate the use of the $\mathrm{pH}$ algorithm described. What might be interesting to consider is whether treatment of this small number of subjects would have been altered had the authors simply monitored signs and symptoms, as mentioned previously.

In a 2003 editorial, Kacmarek ${ }^{5}$ described the many "little things" that can determine the success or failure of patients managed with NIV. Interestingly, the use of costly monitoring techniques was not mentioned as critical in 


\section{Potential Role of $\mathrm{P}_{\mathrm{tcCO}_{2}}$ IN Guiding Acute NIV}

effectively managing patients requiring this type of support. More emphasis was placed on how NIV was applied and the skills that were required to be successful.

van Oppen et $\mathrm{al}^{4}$ should be congratulated for their desire to investigate better methods for monitoring patients with acute hypercapnic respiratory failure. Perhaps if and when the use of this technology and the related $\mathrm{pH}$ algorithm is further investigated and when the equipment expense is reduced, more centers providing NIV will see the utility of $\mathrm{P}_{\mathrm{tcCO}}$ monitoring for managing their patients who require NIV.

Paul F Nuccio MSc RRT FAARC

Department of Respiratory Care Brigham and Women's Hospital Boston, Massachusetts

\section{REFERENCES}

1. Berkenbosch JW, Tobias JD. Transcutaneous carbon dioxide monitoring during high-frequency oscillatory ventilation in infants and children. Crit Care Med 2002;30(5):1024-1027.

2. Eberhard P. The design, use, and results of transcutaneous carbon dioxide analysis: current and future directions. Anesth Analg 2007; 105(6 Suppl):S48-S52.

3. Storre JH, Magnet FS, Dreher M, Windisch W. Transcutaneous monitoring as a replacement for arterial $\mathrm{PCO}_{2}$ monitoring during nocturnal non-invasive ventilation. Respir Med 2011;105(1):143150.

4. van Oppen JD, Daniel PS, Sovani MP. What is the potential role of transcutaneous carbon dioxide in guiding acute non-invasive ventilation? Respir Care 2015;60(4):484-491.

5. Kacmarek RM. Noninvasive positive-pressure ventilation: the little things do make the difference! Respir Care 2003;48(10):919-921. 